\title{
Comunicação
}

[Communication]

\section{Patógenos isolados do trato gastrintestinal de cães saudáveis no Rio de Janeiro}

[Pathogens isolated from gastrointestinal tract of healthy dogs in Rio de Janeiro]

\author{
C.S. Pereira ${ }^{1}$, P.R. Barros $^{2}$, P.M. Silva ${ }^{2}$, D.P. Rodrigues ${ }^{1}$ \\ ${ }^{1}$ Instituto Oswaldo Cruz \\ Av. Brasil, 4365 \\ 21040360 - Rio de Janeiro, RJ \\ ${ }^{2}$ Escola Politécnica de Saúde Joaquim Venâncio - FIOCRUZ - Rio de Janeiro, RJ
}

Vibrio e Aeromonas, importantes patógenos de habitat aquático, têm distribuição mundial e reconhecida emergência em casos de infecção humana, geralmente associada a gastrenterites veiculadas por água e alimentos. Esses microrganismos são isolados com frequência no verão, quando a temperatura ambiente é mais elevada, sugerindo uma característica de sazonalidade (Koelle et al., 2005).

A presente investigação teve por objetivo avaliar a presença de patógenos das famílias Vibrionaceae, Aeromonadaceae e Enterobacteriaceae a partir da emissão de fezes espontâneas de cães saudáveis no Rio de Janeiro.

Foram avaliadas 30 amostras de fezes de 13 cães, com idades variando de um a nove anos, no período de março a junho de 2005. Após coleta asséptica das fezes em frasco estéril e transporte em recipiente isotérmico, as amostras foram encaminhadas para os exames laboratoriais. A coprocultura foi realizada por meio de enriquecimento em água peptonada alcalina adicionada de $1 \%$ e $3 \%$ de cloreto de sódio e caldo Rappaport-Vassiliadis $\left(37^{\circ} \mathrm{C} / 18-24\right.$ h). Em seguida, as amostras foram semeadas em ágar tiossulfato citrato bile sacarose, ágar seletivo para Pseudomonas-Aeromonas, ágar eosina azul de metileno e ágar entérico de Hektoen. Após repique em meios de triagem (kligler iron agar, lysin iron agar e agar costa-vernin), foram realizadas provas de caracterização bioquímica baseadas na fermentação de carboidratos, descarboxilação de aminoácidos, resistência ao agente vibriostático $\quad 0 / 129 \quad(2,4$ diamino $6-7$ diisopropil-pteridina), produção de $\alpha$ nitrofenil$\beta$-D-galactosidase (ONPG) e produção de acetoína em meio Voges-Proskauer (VP) (Abbott et al., 2003).

Foram isoladas 39 cepas bacterianas distribuídas entre os seguintes microrganismos: Escherichia coli (8), Morganella morgani (7), Enterobacter aerogenes (6), Klebsiella pneumoniae (5), Proteus mirabilis (4), Edwardsiella tarda (3), Pseudomonas aeruginosa (2), Citrobacter freundii (1), Aeromonas caviae (1), Vibrio fluvialis (1) e Vibrio sp.(1).

Escherichia coli tem sido isolada a partir de amostras de solo, água e também do trato gastrintestinal de animais domésticos. Diversas cepas podem ser patogênicas e assumir, em algumas condições, caráter zoonótico. Devido a suas características microbiológicas, esse patógeno é utilizado como indicador de qualidade higiênico-sanitária de produtos industrializados. A importância deste achado está associada à ocorrência de osteomielite em cães e gastrenterite humana em indivíduos suscetíveis (crianças, idosos e portadores de doenças crônico-degenerativas), aumentando sua importância para a saúde pública, em particular pela possibilidade de causar infecção hospitalar (Kemper et al., 2006; Lazic et al., 2006; Lara et al., 2008).

Recebido em 23 de setembro de 2008

Aceito em 9 de julho de 2009

E-mail: chrisspm@ioc.fiocruz.br 
Klebsiella pneumoniae e Pseudomonas aeruginosa representam importantes patógenos em episódios gastrentéricos no homem e nos animais, com elevados índices de resistência e multirresistência aos antimicrobianos, especialmente em casos de bacteremia e pneumonia em pacientes hospitalizados (Lincopan et al., 2005).

O isolamento de microrganismos de habitat aquático como Aeromonas caviae e Vibrio fluvialis, isolados no ambiente estudado e em diferentes nichos como solo, alimentos de origem animal e vegetal, animais de sangue frio e mamíferos marinhos, pode assumir relevância epidemiológica pela possibilidade de ocasionar epizootias em sistemas de aquicultura, causando perdas econômicas. Esses patógenos têm sido reconhecidos por causar distúrbios gastrintestinais no homem após consumo de alimentos e água contaminados (Evangelista et al., 2006; Hofer et al., 2006; Pereira et al., 2007).

Embora os microrganismos isolados possam ser considerados como integrantes da microbiota intestinal, aponta-se para a diversidade de patógenos presentes nas fezes dos animais estudados, o que pode representar situação de risco para pessoas suscetíveis, particularmente quando em condições precárias de higiene (Kemper et al., 2006).

Palavras-chave: cão, Vibrio sp., Aeromonas sp, saúde pública

\begin{abstract}
A total of 30 stool samples from 13 healthy dogs were analyzed in order to detect microorganisms in their gastrointestinal tract. The samples were enriched in alkaline peptone water added with $1 \%$ and $3 \%$ sodium chloride and Rappaport-Vassiliadis enrichment broth $\left(37^{\circ} \mathrm{C} / 18-24 \mathrm{~h}\right)$. Then, they were streaked onto Pseudomonas-Aeromonas selective agar base, tiossulfate citrate bile sucrose agar, eosin methylene blue agar, and Hektoen enteric agar. After the biochemical characterization, the results showed 41 bacterial isolated strains, from which Escherichia coli, Vibrio fluvialis, and Aeromonas caviae were the main pathogens encountered.
\end{abstract}

Keywords: dog, Vibrio sp., Aeromonas sp., public health

\section{REFERÊNCIAS BIBLIOGRÁFICAS}

ABBOTT, S.L.; CHEUNG, W.K.W.; JANDA, J.M. The genus Aeromonas: biochemical characteristics, atypical reactions, and phenotypic identification schemes. J. Clin. Microbiol., v.41, p.2348-2357, 2003.

EVANGELISTA, N.S.B.; VIEIRA, R.H.S.F.; CARVALHO, F.C.T. et al. Aeromonas spp. isolated from oysters (Crassostrea rhizophorae) from a natural oyster bed, Ceará, Brazil. Rev. Inst. Med. Trop. São Paulo, v.48, p.129-133, 2006.

HOFER, E.; REIS, C.M.F.; THEOPHILO, G.N.D. et al. Envolvimento de Aeromonas em surto de doença diarréica aguda em São Bento do Una, Pernambuco. Rev. Soc. Bras. Med. Trop., v.39, p.217-219, 2006.

KEMPER, N.; ASCHFALK, A.; HÖELLER, C. Campylobacter spp., Enterococcus spp., Escherichia coli, Salmonella spp., Yersinia spp. and Cryptosporidium oocysts in semi-domesticated reindeer (Rangifer tarandus tarandus) in Northern Finland and Norway. Acta Vet. Scand., v.48, p.7, 2006.
KOELLE, K.; PASCUAL, M.; YUNUS, M. Pathogen adaptation to seasonal forcing and climate change. Proc. Biol. Sci., v.272, p.971-977, 2005.

LARA, V.M.; DONADELLI, M.P.; CRUZ, F.S.F et al. Multirresistência antimicrobiana em cepas de Escherichia coli isoladas de cadelas com piometra. Arq. Bras. Med. Vet. Zootec., v.60, p.1032-1034, 2008.

LAZIC, S.; COBEJELIC, M.; DIMIC, B. et al. Epidemiological importance of human and domestic animals as reservoirs of verocytotoxin producing Escherichia coli. Vojnosanit. Pregl. v.63, p.13-19, 2006.

LINCOPAN, N.; McCULLOCH, J.A.; REINERT, C. et al. First isolation of metallo- $\beta$-Lactamase producing multiresistant Klebsiella pneumoniae from a patient in Brazil. J. Clin. Microbiol., v.43, p.516-519, 2005.

PEREIRA, C.S.; AMORIM, S.D.; SANTOS, A.F.M. et al. Vibrio spp. isolados de mamíferos marinhos capturados na região litorânea do sudeste ao sul do Brasil. Pesq. Vet. Bras., v.27, p.81-83, 2007. 